\title{
Práticas sociais de regulação da identidade do cirurgião-dentista
}

\author{
Social practices for regulation \\ of the dentist's identity
}

Cristine Maria Warmling 1

Sandra Caponi 2

Carlos Botazzo 3

\footnotetext{
1 Faculdade de

Odontologia da Ulbra, Campus Cachoeira. Rua Martinho Lutero 301, Bairro Universitário, 96501-595,

Cachoeira do Sul RS. criswarm@portoweb.com.br

2 Universidade Federal

de Santa Catarina.

3 Instituto de Saúde de São Paulo.
}

Abstract A recurrent problem found in the minutes' reports of the Dental Association of Blumenau, in the decade of the 1960's, is the one related to the confrontation between graduated dentists and practitioners. These confrontational relationships are not exclusive of this city of Santa Catarina state; on the contrary, they were generalized in Brazil and characterize the emergence of a new professional identity in the country. The research combined data arising from different historical sources, such as institutional minutes, legal documents, governmental reports, texts on the history of dentistry, besides interviews and technical books. The reasons that set up the movement of institutionalization and regulation of the profession established a distance between the practices of the graduated dentists and the practitioners, a distance kept by punishment measures created in the name of the monopoly of the dental practice named as true, since scientific. The rupture is established in the name of a new practice, in spite of the fact that the data demonstrate that there is an approximation between the knowledge and the practice accomplished by both studied groups. Key words Dentistry, Dentist practitioners
Resumo Um problema recorrente encontrado nos relatos das atas da Associação Odontológica de Blumenau, na década de 1960, é o que se refere ao confronto entre dentistas formados e práticos. Estas relações de confronto não são exclusivas da cidade catarinense, mas, ao contrário, se generalizaram no Brasil, e caracterizaram a emergência de uma nova identidade profissional no país. Este estudo trata, portanto, do confronto no qual se deu a emergência da regulação e da institucionalização da profissão no século 20, e se propõe a mostrar como estas experiências puderam constituir uma identidade profissional: a do cirurgiãodentista. A pesquisa combinou dados oriundos de diferentes fontes históricas, tais como atas institucionais, documentos jurídicos, relatórios governamentais, obras sobre a história da odontologia, além de entrevistas com práticos e cirurgiõesdentistas, reportagens jornalísticas e livros técnicos. Os argumentos que fundamentam o movimento de institucionalização e regulação da profissão estabeleceram um distanciamento entre as práticas dos formados e as dos práticos, um distanciamento assegurado por medidas punitivas criadas em nome do monopólio da prática odontológica dita verdadeira, porque científica. A ruptura se estabelece em nome de uma nova prática, apesar dos dados demonstrarem que há aproximação entre os saberes e práticas realizados por ambos os grupos estudados.

Palavras-chave Odontologia, Dentistas práticos 


\section{Introdução}

Um problema recorrente no percurso da odontologia brasileira, no âmago do qual se deu a regulação e a institucionalização da profissão no século 20, diz respeito ao confronto entre dentistas formados e os denominados práticos. Este artigo toma como objeto de estudo as relações políticas entre "formados" e "práticos", eventos que se desenrolaram em Blumenau, Santa Catarina, e se propõe a mostrar como essas experiências puderam se constituir como modeladoras da identidade do cirurgião-dentista.

Essas relações de confronto não são exclusivas dessa cidade catarinense; são, ao contrário, generalizadas no Brasil. Elas se mantêm ainda hoje, mas criaram um espaço de debate no longo período que vai desde a década de 1930 até a de 1960. Ao final deste período, a odontologia adquire nova identidade, que se torna hegemônica com o atual modelo de regulação do exercício da profissão no país. Como condição de possibilidade para essa emergência, ocorre, simultaneamente à reorganização da prática, a reorganização do ensino superior da odontologia.

A evolução científica e a regulação profissional foram condições que acentuaram, no Brasil do início do século 20, essas práticas divisoras. Desde o Brasil colonial, diversos dispositivos legais foram ao encontro de uma regulação profissional1, 2. Mas entre os anos 19301960 , as estratégias estabelecidas marcaram fortemente a emergência de uma prática social disciplinadora na área da odontologia.

Para isso, estabelece-se uma ruptura e um deslocamento: da considerada "velha prática" dos práticos para a nova prática técnica, e regulada cientificamente, dos cirurgiões-dentistas, quando uma outra racionalidade odontológica se estabelece e exige a constituição de novos sujeitos, em outros modos de subjetivação. Uma ruptura determinada por eventos que, ao se inter-relacionarem e se combinarem entre si, possibilitaram a emergência e a imposição de um modelo de prática profissional próprio de uma sociedade disciplinar. Se há novos sujeitos e nova subjetividade, teriam também se imposto novas formas de ver ou pensar a profissão? Ou, antes, quais os efeitos dessa nova forma de organização da profissão e como se produziram os novos modos de sujeição da própria saúde bucal?

Existem alguns estudos clássicos que se propõem a interpretar a profissão odontológica a partir de sua perspectiva histórica3, 4. Este estudo, no entanto, procurou aproximar-se daqueles que utilizam a história como um instrumento que possibilita pensar o que pensamos de nós mesmos.

Na pesquisa histórica, voltar ao passado pode ter significados diferentes, dependendo do objetivo a que se propõe o pesquisador. Caponi5, quando estuda o desenvolvimento da assistência médica e seus olhares, que podem ir da compaixão à solidariedade, volta ao passado com um objetivo que nos parece adequado a este estudo: "fazer um uso estratégico da história". Isto significa um olhar histórico com direcionamento ao atual, isto é, com o objetivo de problematizar as suposições tidas como verdadeiras das práticas da atualidade 5 .

Botazzo $^{6}$, ao refletir sobre a emergência da clínica odontológica, mostrou que a história da odontologia, do modo como é contada - ao modo de uma história ingênua - foi determinante para a formação da identidade profissional desde o último quarto do século 19. Nela supõe-se uma proximidade da odontologia com a arte dentária praticada pelos barbeiros a partir da Antigüidade, preservada durante a Idade Média e em crise após a Revolução Industrial, espécie de sucessão a-histórica de descobertas acidentais e de evolução "natural" de um praticante, desde o princípio marcado pelo estigma do existir separado das outras práticas de saúde, sobretudo as médicas e cirúrgicas 6 .

O importante é destacar que, ao mesmo tempo em que se estabeleceram afinidades com os cirurgiões menores e barbeiros, também se estabeleceu, e fortemente neste tipo de pensamento histórico, uma separação em relação aos "praticantes populares", cujas práticas são consideradas inferiores - a despeito de servirem, forçadamente, para justificar um caminho dito evolutivo da profissão, agora transposto ao pensamento histórico e social que se faz dela. Como resultado, esses eventos todos fizeram com que a odontologia mantivesse a marca da ambigüidade - nem exclusivamente dentes, nem plenamente boca, ou "nem exclusivamente odontologia nem plenamente estomatologia"6.

É, portanto, dessa disciplina, e da ambigüidade da relação entre "práticos" e "científicos", que este artigo trata.

\section{Procedimentos metodológicos}

No estudo histórico realizado, combinaram-se dados oriundos de diferentes fontes históricas: 
relatos de atas institucionais, documentos jornalísticos e jurídicos, leis, decretos, entrevistas, relatórios governamentais e também livros técnicos. A análise de fontes diversas permitiu alcançar um conjunto de pontos de vista que delimitaram o campo de verdade referente ao problema da pesquisa, situando-as em relação aos aspectos legais do exercício profissional e ao sistema de ensino.

Quanto aos aspectos legais do exercício da profissão: da regulamentação dos práticos com o presidente Getúlio Vargas, nos anos iniciais da década de 19307 , à instituição legal do órgão oficial de auto-regulação da profissão, o Conselho Federal de Odontologia, em 19648. Há, ainda, os dois dispositivos legais mais importantes desse período para a profissão: a Lei no 1.314 de 17 de janeiro de $1951^{9}$, a primeira a referir-se exclusivamente ao exercício da odontologia; e a Lei no 5.081 de 24 de agosto de $1966^{10}$, que regula o exercício da odontologia até a atualidade.

Quanto ao sistema de ensino: dos cursos de odontologia anexos aos cursos de medicina ou farmácia no início do século, às reformas de ensino que culminaram com a federalização do ensino superior no Brasil11. Estas são algumas das condições de possibilidades que constituem, no âmbito educacional, um modelo disciplinador para a profissão.

Em Blumenau, situa-se a face mais visível do tema tratado: um município de porte médio, com forte influência germânica, que vê precocemente surgir, em seu campo social, discursos e práticas sobre a boca. Os discursos, no microespaço, remetiam a um contexto político, social e científico, desvelando o jogo de poderes e o estabelecimento de estratégias para o enfrentamento de problemas.

As vivências profissionais, tanto dos práticos como dos formados, foram retratadas no sentido de recriar uma dinâmica entre fontes escritas e depoimentos orais, procurando recriar fatos do passado, dando-lhes uma nova dimensão.

\section{Resultados}

\section{Trabalhadores irregulares da saúde bucal}

Relatos de cirurgiões-dentistas encontrados nas atas da Associação Odontológica de Blumenau ${ }^{12}$, por volta da década de 1960 , caracterizam o charlatão ou a prática do charlatanis- mo como uma "chaga social" que deveria ser combatida e controlada. Que características tão perversas aos olhos dos dentistas formados teriam os saberes e práticas dos "charlatães"?

A Associação Odontológica de Blumenau $(\mathrm{AOB})$, entidade local que germinou e se transformou posteriormente na Associação Brasileira de Odontologia (ABO), regional de Blumenau, registra sua preocupação, angústia e indignação ao se referir a esses trabalhadores, e propõe "reiniciar campanha contra o charlatanismo" 12

No dicionário ${ }^{13}$, encontra-se a definição: Charlatão 1. Vendedor público de drogas que exagera ao apregoar-lhes as virtudes. 2. Embusteiro, trapaceiro.

A literatura que se refere aos trabalhos histórico-investigativos de práticas profissionais em saúde retrata diferentes denominações impostas aos profissionais no exercício da sua profissão. Estas denominações, conforme a época e o contexto social referidos, deram um significado aos tipos de saberes e práticas realizados pelos profissionais em seu trabalho com saúde bucal: barbeiros, curandeiros, pseudodentistas, sangradores, tira-dentes, cirurgiões-barbeiros, curadores.

A legislação federal brasileira, posterior à década de 1930, contém um forte movimento de legalização dos dentistas práticos. Neste momento, a denominação referida ao "trabalhador irregular" da odontologia, aquele que não possui formação específica de nível superior para exercer a profissão, é de dentista prático.

No período mais intensamente problematizado pelo estudo, entre as décadas de 1930 e 1960, verificam-se - tanto no âmbito das práticas educativas do cirurgião-dentista como também da sua regulamentação profissional - intensos movimentos nacionais, que convergiam sempre no sentido de adequar fortemente a prática odontológica brasileira à racionalidade científica.

Os formados, ao denominarem os práticos de charlatães, faziam eco a esses movimentos, desejando também marcar as suas diferenças e imprimir um significado à sua luta pelo controle da prática profissional. Uma estratégia utilizada foi desqualificar os práticos, a partir mesmo da denominação a eles imposta.

\section{Práticas bucais em Blumenau}

O "Certificado de Aptidão" de um profissional, que no início do século 20 dedicou-se à arte dentária em Blumenau, foi expedido na re- 
gião de Cöhn, na Alemanha, e encontra-se datado de 1906. Segundo o certificado, a aptidão foi concedida mediante prova escrita e permitia ao profissional o direito de ser titulado: "auxiliar de cura público, testado, massagista e calista qualificado". Até a metade do século 20 , havia ainda poucos profissionais formados em odontologia no município e muitos atendimentos eram realizados por práticos ou mesmo médicos.

Pesquisando números do jornal local $\mathrm{A} \mathrm{Na}$ ção 14 nas décadas de 1950 a 1960, encontramse anúncios de profissionais da área da saúde oferecendo seus trabalhos: "clínica de olhos (nariz, ouvido e garganta), doenças de senhoras, doenças de crianças, doenças do coração, médico operador".

Os cirurgiões-dentistas, por sua vez, mais do que por sua área de atuação, definiam-se por sua técnica: "Raios-X - especialidade em radiografia dentária para qualquer exame médico", "Exame de Raios-X"; ou por sua experiência: "Cirurgião-dentista com 27 anos de prática"14. Nesta época, encontram-se no mesmo jornal os anúncios de formados e práticos, demonstrando relativa harmonia na convivência profissional.

Considerando a origem da qualificação, exerciam a profissão em Blumenau, na década de 1950, diferentes tipos de profissionais: os dentistas práticos que tinham aprendido com outro prático ou mesmo com um dentista formado, e que desenvolviam suas habilidades na própria prática cotidiana, aliando também experiências aprendidas em laboratórios de prótese; os dentistas formados pelo Instituto Politécnico de Florianópolis, entre os anos de 1917 a 193315; e os formados nas faculdades de odontologia, com destaque, nos depoimentos, para a Faculdade de Farmácia e Odontologia de Florianópolis, criada em 194815, e a Faculdade de Odontologia do Paraná, criada em 191211.

\section{A formação para as práticas bucais}

Assim como no Instituto Politécnico, o conteúdo curricular do curso oferecido pela Faculdade de Farmácia e Odontologia durante todo o seu período de funcionamento, dos anos 1945 a 1966, nunca foi modificado, mantendose com duração total de três anos durante um período de dezoito anos. Após a federalização da universidade e a separação das Faculdades de Farmácia e Odontologia, houve uma mudança curricular e o curso passou a ser ministrado em quatro anos, o que ocorreu apenas em 196615.
O modelo de formação preconizado, apesar de ter sido concebido inicialmente na estrutura física do Departamento Estatal de Saúde Pública, tinha seu eixo pedagógico baseado fortemente no desenvolvimento da habilidade manual. As grades dos cursos evidenciam uma valorização do treinamento prático do aluno, predominando as disciplinas com caráter técnico.

O perfil do profissional formado pelas três propostas (do Instituto, da Faculdade de Farmácia e Odontologia e, por fim, da Faculdade de Odontologia), não sofreu alterações marcantes no período estudado. Os currículos, com forte tendência ao tecnicismo, demonstram haver proximidade entre as práticas profissionais, independentemente do acesso ou não à formação. De fato, ambos os grupos entrevistados praticavam uma odontologia essencialmente restauradora e voltada para a doença.

\section{Dos espaços odontológicos à sociabilidade da cárie}

Os depoimentos dos práticos e dos formados traduzem os problemas exigidos da prática odontológica no período circunscrito, entre as décadas de 1950 e 1960, mas, antes de tudo, evidenciam como cada grupo profissional respondia às demandas.

Os práticos relatam uma alta demanda da população pelo atendimento odontológico e um número pequeno de profissionais para suprir esta necessidade. Esses problemas se agravavam nas áreas rurais onde, segundo eles, havia dificuldades de acesso a esse tipo de atendimento: Eu trabalhava com meu pai, conforme o movimento. Dependendo, eu virava de domingo a domingo. Não tinha dia nem hora ou sábado. O movimento era igual ao de hoje no Inamps. Tinha uma fila na porta 16 .

Nos depoimentos dos formados não prepondera a questão da alta demanda da população por atendimento. Suas preocupações mais evidentes estão direcionadas à qualificação de seu trabalho profissional: Não havia informações. Era difícil. Até para mim. Foi um período difícil de iniciar a minha atividade em Rio do Sul. Segundo me consta, eu era o único formado pela universidade, de Lages a Blumenau. Um período dificil de trabalhar no interior 16 .

O dilema caracterizava-se: como qualificar a prática e ao mesmo tempo oferecer respostas à população, que demandava atendimento?

Assim os dentistas formados ocupavam parte de suas discussões na $\mathrm{AOB}$ a construir pro- 
postas caritativas de intervenção social: Fala o Dr. OV, dizendo da sua vontade de instalar nesta cidade um consultório dentário para o atendimento de indigentes. É apartado pelo colega $\mathrm{OH}$, o qual diz já estar a cidade bem suprida desses consultórios, pela prestação de serviços de entidades assistenciais: Centro de Saúde, Sesi, Fábricas. Apesar disso, estudou-se como se faria isto, prometendo o colega A doar dez fórceps, o colega $\mathrm{OH}$ um aparelho de raios infravermelhos, o colega $P$ duas horas de serviços por semana, o colega $D$ uma caixa de anestésico de 50 tubos. Entretanto, dado a inúmeras dificuldades, o assunto deverá ser estudado posteriormente16.

As falas descrevem espaços diferentes dos habituais consultórios odontológicos privados, usualmente reservados para a prática odontológica. Esses novos espaços estavam relacionados com as características socioeconômicas da cidade. Um tempo marcado pelo desenvolvimento industrial e de aparelhagem estatal. Considerada cidade fabril, Blumenau cresceu ancorada na indústria têxtil, e, assim, a maioria dos espaços de atendimento odontológico encontrava-se fortemente vinculada às fábricas, aos sindicatos, ao Serviço Social da Indústria (Sesi) 17 , e esse movimento se constituiu em conjunto com o crescimento do papel regulador do Estado na área da saúde. Também foram criados novos espaços estatais entre as décadas de 1950 e 1960: os Centros Sociais Urbanos, o Centro de Saúde e, ao final da década de 1960, os consultórios odontológicos que começavam a ser estabelecidos em escolas para o atendimento aos alunos 17.

\section{$\mathrm{O}$ caso RZ - uma relação de forças}

Entre os casos de perseguição a práticos encontrados, citados nas atas da AOB, um deles tomou mais tempo e discussão dos associados e exigiu o estabelecimento de táticas específicas para a coibição da sua prática: 06/04/1965 [...] apesar de vários avisos, o charlatão $R Z$ continua a trabalhar ilegalmente, havendo necessidade de reabrir o seu caso ${ }^{12}$. 30/11/1965 - [...] Foi a reunião convocada para apreciar o caso do charlatão $R Z$, que recentemente, em Florianópolis, foi autuado tentando falsificar documento que o habilitasse a exercer a odontologia, usando fotocópia de diploma [...] fará uma denúncia ao Centro de Saúde no dia dez de dezembro 12 . 07/12/1965 - [...] tratou-se de artigo a ser publicado na imprensa local, sobre a recente prisão do charlatão RZ12. 18/10/1966 - [...] solicitação do promotor referente à necessidade de conseguirem testemunhas contra os dentistas ilegais para facilitar o processo contra os mesmos [...] sugerese a ida a Florianópolis para buscar o fichário apreendido do $R Z$ para funcionar como localização das testemunhas ${ }^{12}$. 18/10/1969 - [...] o delegado do CRO [...] comunicou as providências tomadas a fim de cumprir a lei. Comunicou aos presentes a apreensão de materiais e instrumentos do Sr. RZ, que vinha exercendo ilegalmente a profissão de dentista na Vila Itoupava [...] ainda comunicou das atividades ilegais do Sr. AD, com instalação na Velha. Ficou decidido da ampla divulgação na imprensa escrita e falada 12 .

Diante da fragilidade das estruturas legais de controle do exercício da profissão, os próprios formados, através da associação, assumiam a responsabilidade da ação fiscalizadora. $\mathrm{Na}$ opinião dos formados, as estruturas reguladoras eram morosas ou mesmo ineficazes.

Os dentistas formados recorriam à imprensa escrita para comunicar à sociedade o ocorrido. A carta publicada no jornal A Nação, no dia $17 / 12 / 1965$, relatou o processo de cassação do dentista prático RZ. Os formados desejavam alertar a sociedade quanto à necessidade de uma melhor organização do controle estatal da prática profissional. A carta não trazia referência a imperícia ou mesmo a erro odontológico, supostamente cometido por RZ. Alguns comentários das atas referiam-se ao levantamento de testemunhas, mas em nenhum momento apareceu o relato de situação de prejuízo à saúde de algum paciente de RZ ou de qualquer outro prático citado.

RZ também exerceu seu poder, através do direito de resposta, enviando, no dia seguinte, um artigo em sua defesa para o mesmo jornal.

Para os dentistas formados, a luta pela legalização da odontologia não era valorizada pela sociedade. A sociedade não via o perigo que representavam os dentistas práticos. Os práticos detinham prestígio e poder, pois suas práticas eram bem respaldadas socialmente. Ela era vista como nem sendo muito necessária, foram os primeiros profissionais que se formaram dentro de uma escola oficial e até então a sociedade aceitava assim, aquela odontologia feita com menos rigor científico, como uma coisa normal16.

A sociedade não condenou RZ e ele continuou a exercer a sua profissão até quase sua morte, assim como outros práticos que vieram a surgir e se manter no mercado até a atualidade, inclusive seu filho.

Alguns dias depois da publicação das cartas de ataque e defesa do caso RZ, o jornal $A \mathrm{Na}$ - 
ção divulgou editais de inscrição para o curso de odontologia, publicados pela Faculdade de Odontologia. Entre outras informações, constavam que as inscrições, e até mesmo as provas, poderiam ser realizadas na própria associação odontológica.

As ações de perseguição aos práticos, muitas vezes próximas da arbitrariedade, estavam articuladas à institucionalização do ensino, à formação de um código odontológico legal próprio e à criação de um órgão fiscalizador corporativo. Foi esta rede de acontecimentos que propiciou à odontologia emergir com as características que possui na atualidade.

\section{Discussão}

A prática odontológica realizada no país vem sendo estudada e criticada ao longo de diversos encontros de debate e reflexão a seu respeito. $\mathrm{Na}$ VII Conferência Nacional de Saúde, realizada em Brasília, em 1980, esse modelo foi caracterizado, em traços gerais, pela ineficácia, ineficiência, descoordenação, má distribuição, baixa cobertura, alta complexidade, enfoque curativo e mercantilista, caráter monopolista e inadequação no preparo dos recursos humanos ${ }^{18}$.

Botazzo repensou as críticas que têm sido feitas à odontologia brasileira, no sentido de que elas pouco questionaram ou estudaram as condições de possibilidade ou de existência dessa formação. É que as análises que até o presente tomaram a prática odontológica como objeto admitem a sua existência no tempo como um a priori, historicamente dado, mas igualmente não questionado6.

Estudos reconhecidamente clássicos da história da profissão odontológica, como os de Lerman $^{3}$ ou mais atualmente os de Ring 4 , procederam, de certa forma, com suas grandes e intermináveis séries históricas, a naturalização da compreensão das práticas odontológicas. Baseando-se nesses estudos, a explicação histórica "natural" para a supressão dos práticos colocou a evolução científica como a razão preponderante e, portanto, aceitável para o cerceamento dessas práticas profissionais.

Para proceder a desnaturalização desse acontecimento, é necessário desviar o olhar para as suas singularidades e tratá-lo como um fato raro. Esse novo procedimento do olhar permite distinguir práticas datadas e envoltas pela trama política da época. Pensar esse problema não como fato histórico, mas como um aconteci- mento singular e datado, exige pensá-lo nos seus aspectos mais microssociais, aspectos esses que mudam a forma usual de pensar sobre ele ${ }^{19}$.

Tomar o objeto de pesquisa no seu eixo histórico, a partir da teorização de Foucault20, usando seu pensamento de forma "que sirva, que funcione", pressupõe a recusa a uma visão de história universal, evolutiva e totalizante. Não interessa buscar o ponto de origem fundante, mas sim o que se torna emergente. Assim, seus estudos dão um caráter especial às práticas. São as práticas que produzem os objetos. As práticas se impõem sobre os objetos. São sempre datadas, ou seja, relativas a uma conjuntura, que, por sua vez, faz com que elas sejam o que são. As práticas mudam historicamente conforme a trama política, produzindo figuras históricas heterogêneas, como num mecanismo calidoscópico, que lança imagens múltiplas produzidas pela combinação entre a reflexão de seus fragmentos móveis de vidro colorido e o seu jogo de espelhos ${ }^{19}$.

Sob essa perspectiva, é num espaço de poder político que se circunscreve a explicação para a perseguição aos dentistas práticos. Mas é preciso buscar o que esteve invisível, e nem por isso oculto, nesse espaço político, para então permitir que possa ocorrer o surgimento do inesperado, "do bibelô político de época", nas palavras de Veyne21. Proceder ao afastamento da essencialização do objeto é, pois, colocar o foco nas práticas que o produziram, torná-las visíveis.

Esse desprendimento do objeto naturalizado provoca um afastamento das explicações comumente encontradas na história da profissão. Um movimento de afastamento e deslocamento que nos leva a um outro objeto, um objeto no qual se identificam políticas de verdade, relações entre poder e saber, e a identidade do odontólogo moderno sendo cunhada nesse interstício.

Nesse sentido, através da recriação de uma história que tomou como ponto de partida o embate ocorrido entre os dentistas formados e os práticos num município brasileiro, tentamos problematizar o modo pelo qual fomos constituídos como sujeitos dessa prática odontológica.

\section{Considerações finais}

As relações de confronto entre os dentistas práticos e formados foram, de certa forma, expressões das relações de poder e de saber que se estabeleceram no período de emergência e discipli- 
namento da profissão, nas suas características mais modernas. Uma outra modalidade de racionalidade da prática odontológica se estabelecia, exigindo a constituição de outros sujeitos.

Os saberes e práticas sobre a boca foram constituídos socialmente, e seu exercício, em conexão com os acontecimentos gerais, forçou o caminho da profissão para o confinamento nas instituições, nas leis profissionais, no ensino.

A modificação do cenário se deu predominantemente pelo fortalecimento das práticas de institucionalização da odontologia. A escola assumiu sua função na rede de poderes e práticas sociais de regulação da odontologia moderna e científica.

Quando os formados postulavam a separação dos práticos e a regularização da profissão, quando argumentavam em nome de uma prática mais científica, quando se utilizavam das redes de poder que estavam ao seu alcance para incitar a sociedade a se posicionar ao seu lado, desejavam, antes de tudo, estabelecer um diferencial, propor uma nova prática. Porém, essa prática diferente não foi, então, tão claramente diferenciada.

Pretendia-se uma ruptura e, no entanto, estabeleceram-se vários pontos de continuidade. A concepção de trabalho dos práticos não mudou substancialmente na odontologia institucionalizada. A reformulação do oficio dos práticos para demarcar a superioridade da prática dos formados se direcionou, prioritariamente, para uma agregação tecnológica. Nas propostas curriculares dos cursos de odontologia, oferecidos no período estudado, permanece o enfoque que privilegia o aperfeiçoamento manual.

Os argumentos e eventos que fundamentaram o movimento de institucionalização e regulação da profissão, e pretendiam estabelecer o distanciamento entre as práticas dos dois grupos, foram assegurados por práticas punitivas. Os dados demonstram que havia aproximação entre os saberes e práticas realizados por ambos os grupos estudados.

A prática dos formados não era socialmente aceita. A preocupação dos formados com a participação social apontava para a necessidade de legitimação de seu espaço profissional. Os depoimentos encontrados nas atas da AOB, quando se referem à odontologia social, traduzem uma visão basicamente caritativa.

Mesmo nas reuniões descritas nas atas, as discussões não descrevem as práticas dos práticos: o interesse é essencialmente voltado ao combate do exercício ilegal e ao aperfeiçoamento dos mecanismos coercitivos.
Movimentos mais intensos de questionamentos das práticas odontológicas só vieram a acontecer posteriormente, com propostas no campo da odontologia preventiva e, finalmente, nos tempos atuais, com a saúde bucal coletiva, que se encontra ainda no seu estágio de construção teórica.

Os discursos preventivos e suas biopolíticas (a fluoretação das águas como exemplo mais marcante), apesar de se mostrarem presentes, não conseguiram sobrepujar, em termos de importância, os discursos da regulação profissional. Mesmo que este fosse um dos pontos em que se encontrou um grau de diferenciação entre os saberes praticados pelos grupos estudados. O momento histórico estudado demonstra, mais uma vez, a necessidade da odontologia primeiro se firmar como parte, como disse Botazzo, para depois, como parte, tentar definir-se como totalidade6.

Essa parece ser uma vertente importante, que poderia ser mais bem explorada por futuros trabalhos que desejassem verificar como procederam, no nível local, os movimentos que propuseram práticas odontológicas preventivas.

$\mathrm{Na}$ opinião dos formados, o tempo foi fazendo com que se aposentassem [os práticos] e outros ocupassem seu espaço. Mas os objetivos dos formados não deixaram de ser alcançados. Houve, sim, o completo fortalecimento e institucionalização do ensino odontológico, concomitantemente à regulamentação, e a prática social emergiu deste período com uma nova roupagem, apoiada no senso científico e pronta a responder às necessidades de uma sociedade disciplinadora.

Mesmo com o sistema de regulamentação constituído e o sistema de ensino completamente organizado, e formando um número expressivo de profissionais para a área, existem dados comprovando um grande número de práticos exercendo a profissão no Brasil da atualidade 22 , mas este deixou de ser um problema central. Novas transformações da sociedade exigirão novas respostas reguladoras e novas práticas de poder e controle para a corporação se preocupar.

Os práticos não oferecem mais o risco que representavam no passado, para uma prática fortemente institucionalizada e legalizada como a encontrada na atualidade. Mas, de certa forma, os problemas que a sociedade disciplinar não conseguiu resolver com sua odontologia científica retornam, hoje transformados, como as clínicas populares ou o grande número de faculdades. 


\section{Colaboradores}

CM Warmling trabalhou na execução da pesquisa, elaboração e redação final do texto. C Botazzo participou da revisão bibliográfica, organização e redação final do texto. S Caponi participou na execução da pesquisa e na revisão bibliográfica.

\section{Referências}

1. Oliveira AE. Alguns elementos históricos de um personagem: o cirurgião dentista, a corporação odontológica e o seu imaginário [dissertação]. Vitória (ES): Universidade Federal do Espírito Santo; 1991.

2. Freitas SFT. História social da cárie dentária. Bauru: Edusc; 2001.

3. Lerman S. História de la odontologia y su ejercicio legal. 2a ed. Buenos Aires: Mundi; 1964.

4. Ring ME. História ilustrada da odontologia. São Paulo: Manolo; 1998.

5. Caponi, S. Da compaixão à solidariedade: uma genealogia da assistência médica. Rio de Janeiro: Fiocruz; 2000.

6. Botazzo C. Da arte dentária. São Paulo: Hucitec, Fapesp; 2000.

7. Brasil. Conselho Federal de Odontologia. Decreto no 20.862 de 28 de dezembro de 1931. Regula o exercício da odontologia pelos dentistas práticos. Diário Oficial [da] República Federativa do Brasil 1931;29 dez.

8. Brasil. Lei Orgânica no 4.324 de 14 de abril de 1964 Institui o Conselho Federal e os Conselhos Regionais de Odontologia, e dá outras providências. Diário Oficial [da] República Federativa do Brasil 1964; 15 abr.

9. Brasil. Decreto-lei no 1.314 de 17 de janeiro de 1951 Regulamenta o exercício profissional dos cirurgiõesdentistas. Diário Oficial [da] República Federativa do Brasil 1951; 18 jan.

10. Brasil. Decreto-lei no 5.081 de 24 de agosto de 1966. Regula o exercício da odontologia. Diário Oficial [da] República Federativa do Brasil 1966; 26 ago.

11. Guimarães P. O ensino odontológico no Brasil. Rio de Janeiro: Capes; 1961.
12. Associação Brasileira de Odontologia. Regional Blumenau. Livros de atas. Blumenau; 1964-1973.

13. Ferreira ABH. Miniaurélio século XXI: o minidicionário da língua portuguesa. 4a ed. Rio de Janeiro: Nova Fronteira; 2000.

14. A Nação. Blumenau: Arquivo Histórico José Ferreira da Silva; 1950-1960.

15. Rosa JE, Madeira A. Odontologia catarinense: evolução, ensino e movimento associativo. Florianópolis: Ed. da UFSC, 1982.

16. Caderno de entrevistas. Blumenau; jan 2002.

17. Relatórios do Governo Municipal. Blumenau: Arquivo Histórico José Ferreira da Silva; 1940-1970.

18. Narvai PC. Odontologia e saúde coletiva. São Paulo: Hucitec; 1994.

19. Bock M, Warmling CM. A pesquisa pós-estruturalista e o pensamento histórico de Michel Foucault. Florianópolis: Anais Digitais Seminário Michel Foucault; 2004.

20. Foucault M. Nietzsche, a genealogia e a história. In: Machado R, organizador. Microfísica do poder. 3a ed. Rio de Janeiro: Graal; 1982.

21. Veyne P. Foucault revoluciona a história. In: Veyne P. Como se escreve a história. 3a ed. Brasília: Ed. da UnB; 1995.

22. Carvalho CL. Dentistas práticos no Brasil: história de exclusão e resistência na profissionalização da odontologia brasileira [tese]. Rio de Janeiro: Escola Nacional de Saúde Pública, Fundação Oswaldo Cruz; 2003.

Artigo apresentado em 25/07/2005

Aprovado em 30/08/2005

Versão final apresentada em 9/09/2005 